\title{
Age and gender distribution of pterygium cases from the pterygium surgery social service program
}

\author{
Supanji, ${ }^{1,2}$ Tania Purbonegoro, ${ }^{1}$ Anindita Dianratri, ${ }^{1}$ Krisna Dwi Purnomo Jati, ${ }^{1,2}$ Agung Saputro, ${ }^{1,2}$ \\ Aloysius Angga Wibowo, ${ }^{1,2}$ Suhardjo,
}

\author{
${ }^{1}$ Department of Ophthalmology, Faculty of Medicine, Public Health, and Nursing, Universitas Gadjah Mada, Yogyakarta, \\ Indonesia \\ ${ }^{2}$ Ophthalmology Clinic, Dr. Sardjito General Hospital, Yogyakarta, Indonesia
}

ACCEPTED: 20 April 2021

KEYWORDS

Age

Gender

Gunung Kidul

Pterygium

Yogyakarta
ABSTRACT Pterygium is an eye condition that causes abnormal growth of fibrous tissue on the sclera. Pterygium could cause vision impairment when it reaches the area that blocks the pupil. Though the cause is still inconclusive, pterygium is associated with older age and male gender. The incidence of pterygium in Yogyakarta remains relatively unreported due to little documentation. This study aimed to report findings from the Pterygium Surgery Social Service Program, focusing on the age and sex distribution from several communities in Gunung Kidul, Yogyakarta. This study was a descriptive cross-sectional study. Study subjects were pterygium patients from the social service program organized by the Department of Ophthalmology, Faculty of Medicine, Public Health, and Nursing, Universitas Gadjah Mada, in October 2018 - March 2020. There were 227 patients consisted of 151 female patients (66.5\%) and 76 male patients (33.5\%). There were 22 patients $(9.7 \%)$ who had grade I pterygium, 137 patients $(60.4 \%)$ had grade II pterygium, 45 patients (19.8\%) diagnosed as having third-grade pterygium, and 23 patients $(10.1 \%)$ had grade IV pterygium. On average, female patients made a higher proportion of those having pterygium in all grades. The majority of patients in all age groups fell into second-grade pterygium, except for those aged $>70$ years old who had a higher number of those in the grade III category. In conclusion, female subjects made a higher proportion than males in all pterygium grades, and those aged 70 years and older had a more severe stage.

(c) The Journal 2021. This article is distributed under a Creative Commons Attribution-ShareAlike 4.0 International license.

\section{Introduction}

Pterygium is a type of fibrovascular benign growth that develops on the outermost membrane of the eye, which is often located on the nasal area. ${ }^{1,2}$ Though it is primarily a benign disease, visual complaints could occur when it grows through the visual axis, thus affecting one's quality of life. The specific cause of pterygium remains inconclusive. However, several studies reported few correlating factors, such as sun exposure, the residence of tropical countries, increased age, and male gender. ${ }^{1-3}$ Ultraviolet (sun) exposure along with dry and windy weather causes constant irritation to the eye, leading to pterygium growth. Therefore, someone who work outdoors,

\footnotetext{
*Correspondence: supanji@mail.ugm.ac.id

Department of Ophthalmology, Faculty of Medicine, Public Health, and Nursing, Universitas Gadjah Mada

Jl. Farmako, Sekip Utara, Yogyakarta 55281, Indonesia
}

such as farmers and fishers, were exposed to more eye irritants than those who work indoor. ${ }^{4}$

Indonesia is a tropical country that theoretically should have a reasonably higher number of pterygium cases. According to the Indonesian Basic Health Statistic (RISKESDAS) year 2015, Indonesia had a pterygium prevalence of $8.3 \%$ nationally. ${ }^{4}$ The three highest provinces with pterygium cases were Bali (25.2\%), Maluku (18.0\%), and Nusa Tenggara Barat (17.0\%). Compared to other Asian countries, Indonesia had a lower prevalence of pterygium cases than Japan (30\%), Tibetans' China (15\%), and Mongolians' China at $18 \% .^{5}$

According to Riskesdas 2013, Yogyakarta has an overall pterygium prevalence of $14.1 \%{ }^{5}$ Gunung Kidul made the highest number at $26.9 \%$, followed by Bantul (15.6\%), Kulon Progo (15.2\%), Kota Yogyakarta (7.9\%), and Sleman (7.0\%). Gunung Kidul had a much 
higher prevalence of pterygium compared to other districts in Yogyakarta.

In recent years, few reports were available to see the demographic changes of pterygium cases in the region. Therefore, we tried to document our findings from the Pterygium Surgery Social Service Program in Gunung Kidul. The program was a joint charity action between the Department of Ophthalmology Faculty of Medicine, Public Health, and Nursing (FKKMK), Universitas Gadjah Mada (UGM), Dr. Sardjito General Hospital, Public Health Agency of District Gunung Kidul, and National Amil Zakat Agency (BAZNAZ) Gunung Kidul. This program was held in Gunung Kidul because most of the residents are working outdoors and exposed to the sun for hours, so pterygium prevalence is the highest among other districts in the Special Region of Yogyakarta. Their knowledge regarding pterygium, such as risk factors, prevention, management, and prognostic, is far from enough so that patients come to health facilities with pterygium tissue already covering the visual axis. This program also aimed to reach out to as many patients as possible to give health access to those who previously could not due to transportation and cost-related barriers.

Our focus in this study was to describe the age and gender distribution among those diagnosed with pterygium. We also provided little documentation on occupation distribution and the associated risks according to the pterygium grading.

Pterygium is a problem that is easily diagnosed early by general population. With the data from this study, we can strengthen education to the public about risks, prevention, and management options in managing pterygium before it is too late and complicates handling. The target of community empowerment from the results of this study is to provide awareness to the general public and strengthen the role of general practitioners in diagnosis and prevention. However, some challenges will arise, such as difficult access to an advanced health center, due to remote locations and limited transportation. We hope to resolve this problem with a pterygium surgery social service at the primary health care.

\section{Method}

We used a cross-sectional descriptive method for this study. We recruited all participants who had pterygium of any degree from the Pterygium Surgery Social Service Program from October 2018 - March 2020. The joint program was held in seven subdistricts in the Gunung Kidul district, Yogyakarta. Each sub-district was given an allocated date to keep the program. Wonosari sub-district had the program on 27 October 2018, Gedangsari was on 16 February 2019, Tepus was on 23 March 2019, Nglipar was on 14 July 2019, Ponjong was on 9 November 2019, Patuk was on 29 December 2019, and Paliyan was on 1 March 2020. However, due to incomplete data, the final analysis only used participants from 5 subdistricts: Gedang sari, Tepus, Nglipar, Ponjong, and Patuk.

Recruitment of patients for the Pterygium Surgery Social Service Program began with BAZNAS registering data on residents who have complaints of visual impairments to come to the nearest primary public health center (PUSKESMAS). All participants
Initial participants (363):
1. Wonosari (53 participants)
2. Paliyan (51 participants)
3. Gedang Sari (68 participants)
4. Tepus (52 participants)
5. Nglipar (53 participants)
6. Ponjong (62 participants)
7. Patuk (24 participants)

Figure 1. Data collection scheme

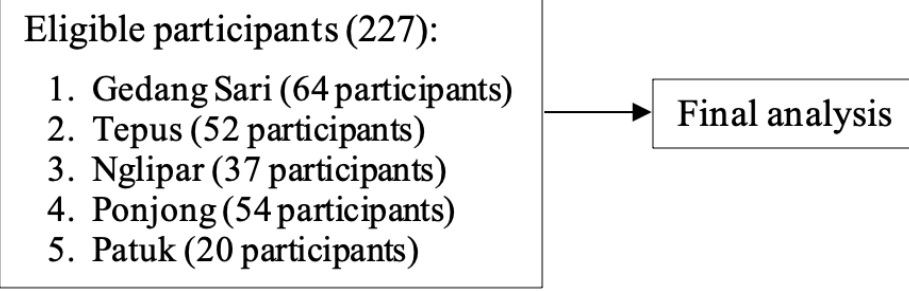

Eligible participants (227):

1. Gedang Sari (64 participants)

2. Tepus (52 participants)

4. Ponjong (54 participants)

5. Patuk (20 participants) 
underwent a series of standard ophthalmologic examinations, consisting of a Visual Acuity (VA) test using a Snellen chart, penlight, and ophthalmoscopic examination, by an ophthalmology resident then subsequently confirmed by an ophthalmologist. All participants having any level of pterygium were operated for free.

Pterygium diagnosis was classified into four grades according to the surface area affected, grade 1 being the mildest and grade 4 the most severe. We noted the age, gender, occupation, the eye affected (right or left), and the pterygium grades of each participant for analysis. A statistical $\chi^{2}$ test was utilized for easier understanding.

Eligibility criteria for patients who will undergo surgery are patients with any pterygium grade and who want to do surgery under local anesthesia. Exclusion criteria from surgery were if the lesion was suspected to be malignant, the patient had a history of blood clotting disorders, and an active intraocular inflammatory condition.

The study was designed following the tenets of the Declaration of Helsinki, and the protocol was submitted and approved by Universitas Gadjah Mada Ethics Committee (Protocol number: KE/0197/03/2021). All patients who agreed to have their surgery have gone through the consent by informed consent.

\section{Result}

\subsection{Tables}

The mean age was $53.84 \pm 10.91$ (range: $29-81$ ) years old. Female subjects comprised a higher proportion of the overall subjects with 151 subjects (66.5\%). Thus, resulting in a male to female ratio of 1:1.99 (Table 1, Table 2).

The majority of subjects were farmers (74.9\%), which primarily work outside of the house with significant sun exposure during the daytime. Others work various jobs that are mostly indoor. We did a chi-square test to see the significance of sun exposure to the disease severity. The result showed that sun exposure did not correlate to disease severity $(p>0.05)$. (Table 3 )
Table 1. Baseline characteristics

\begin{tabular}{ll}
\hline Variable & Values (n=227) \\
\hline Age group, y (\%) & $30(13.2 \%)$ \\
$<40$ & $53(23.3 \%)$ \\
$40-50$ & $83(36.6 \%)$ \\
$51-60$ & $45(19.6 \%)$ \\
$61-70$ & $16(7.0 \%)$ \\
$\geq 70$ & \\
Gender (\%) & $151(66.5 \%)$ \\
Female & $76(33.5 \%)$ \\
Male & \\
Eye affected (\%) & $116(51.1 \%)$ \\
RE & $111(48.9 \%)$ \\
LE & \\
Pterygium grading (\%) & $22(9.7 \%)$ \\
Grade I & $137(60.4 \%)$ \\
Grade II & $45(19.8 \%)$ \\
Grade III & $23(10.1 \%)$ \\
Grade IV & $170(74.9 \%)$ \\
Occupation (\%) & $28(12.3 \%)$ \\
Farmers & $6(2.6 \%)$ \\
Housewives & $14(6.2 \%)$ \\
Entrepreneurs & $8(3.5 \%)$ \\
Laborers & $1(0.4 \%)$ \\
Private Sector & \\
Others &
\end{tabular}

\subsection{Graphs}

Those in the fifties comprised the majority of the subjects with a percentage of $36.6 \%$, followed by those in the forties (23.3\%), sixties (19.6\%), before forties (13.2\%), and over seventies (7.0\%). The majority of subjects fell into the second grade of the pterygium staging $(60.4 \%)$, followed by the third grade $(19.8 \%)$, the fourth grade $(10.1 \%)$, and the first grade $(9.7 \%)$. (Figure $1-3$ )

Those who work outdoors have a higher proportion of pterygium (74.9\%) than those working indoors (25.1\%). (Figure 4)

\section{Discussion}

Our study documented an older mean age of participants, which was 53.84 years old compared to a similar survey conducted in Riau, which was 42.9 years old. The Riau study reported that most participants work as fishermen who started working at a younger age and rarely wear sunglasses or protective goggles while free diving. Compared to this study, most subjects work as farmers, and no one was a fisherman. The younger onset of pterygium 
Table 2. Data on age, sex, and eye effected

\begin{tabular}{lllll}
\hline \multirow{2}{*}{ Age Group (years old) } & \multicolumn{2}{l}{ Gender $(\mathbf{n})$} & \multicolumn{2}{c}{ Eye Effected $(\mathbf{n})$} \\
\cline { 2 - 5 } & Male & Female & Right Eye & Left Eye \\
\hline$<40$ & 9 & 21 & 15 & 15 \\
$40-50$ & 18 & 35 & 33 & 20 \\
$51-60$ & 29 & 54 & 37 & 46 \\
$61-70$ & 15 & 30 & 28 & 17 \\
$>70$ & 5 & 11 & 8 & 8 \\
\hline
\end{tabular}

n: number of subjects

Table 3. Sun-exposure to pterygium grades analysis

\begin{tabular}{lllll}
\hline & $\begin{array}{l}\text { Outdoor Jobs } \\
(\mathbf{n = 1 7 0 )}\end{array}$ & $\begin{array}{l}\text { Indoor Jobs } \\
(\mathbf{n = 5 7 )}\end{array}$ & $\mathbf{p}$ & OR \\
\hline Pterygium grades, $\mathrm{n}(\%)$ & $14(8.2 \%)$ & $8(14.0 \%)$ & ref & ref \\
Grade 1 & $102(60.0 \%)$ & $35(61.4 \%)$ & 0.291 & $0.23-1.63$ \\
Grade 2 & $35(20.6 \%)$ & $10(17.5 \%)$ & 0.221 & $0.16-1.80$ \\
Grade 3 & $19(11.2 \%)$ & $4(7.07 \%)$ & 0.150 & $0.08-1.51$ \\
\hline
\end{tabular}

n: number of participants; p: p-value; OR: odds ratio

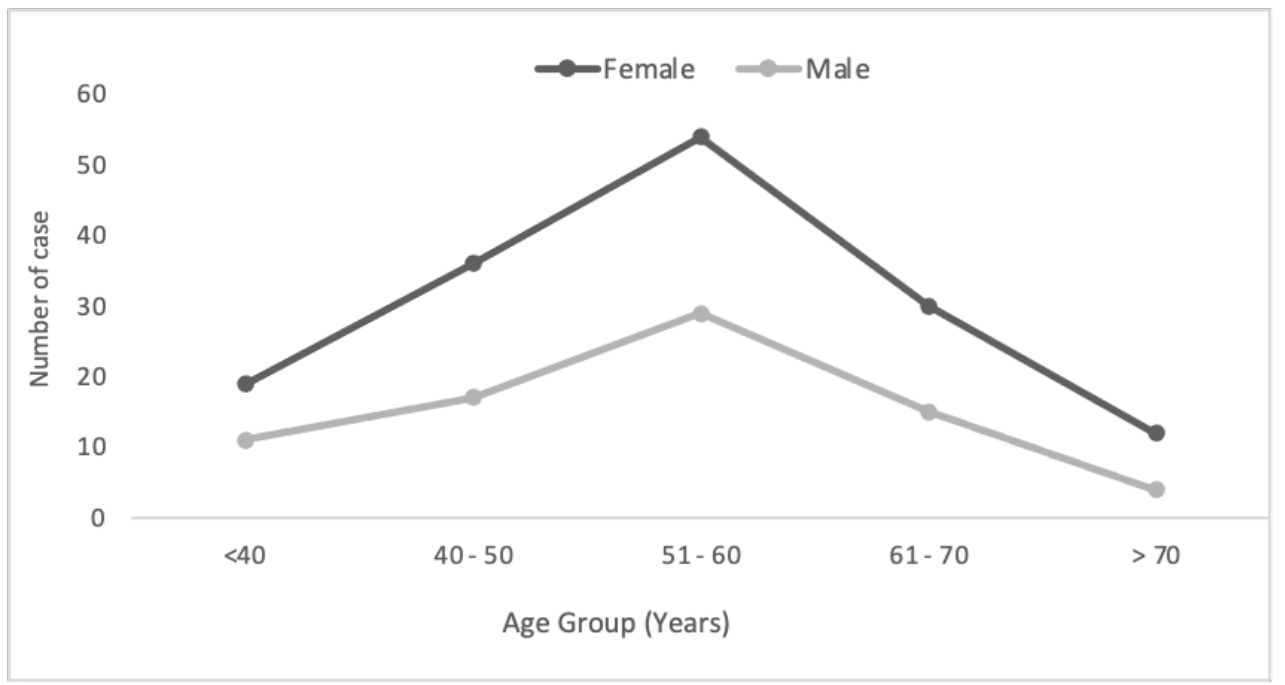

Figure 1. Age and gender distribution of the study subjects

in Riau could be due to more prolonged exposure to irritants such as sun exposure, dry and windy weather in the shores, and seawater during ungeared diving. While farmers in Gunung Kidul might be more exposed to the sun than those working indoors, the fishermen from the Riau study were more at risk due to added factors such as weather on the shore and the seawater. ${ }^{6,7}$

The number of subjects in this study aged $>50$ years old was 1.74 times higher than those $<50$ years old. The number of pterygium cases also increased with the increasing decade. The majority of the subjects were $51-60$ years old $(36.6 \%)$, but the number steadily decreased in the seventh (19.6\%) and the eighth decades (7\%). Compared to the Riau study, the number of cases peaked in the fourth decade (6). In South Korea, the prevalence peaked in the eighth decade. ${ }^{8-10}$ This shows that older age increased the prevalence of pterygium and peaked at a certain decade. However, the peak decade is different for each region. Many factors could contribute to the different peak ages, but one possible cause might be the difference in life expectancies from each region. Life expectancy for Gunung Kidul was 73.92 years old, Riau Islands was 69.45 years old, and South Korea was 83.5 years old. ${ }^{12-16}$ The type of work might also influence the peak age. Residents in Gunung Kidul and Riau Islands mostly work outdoors 


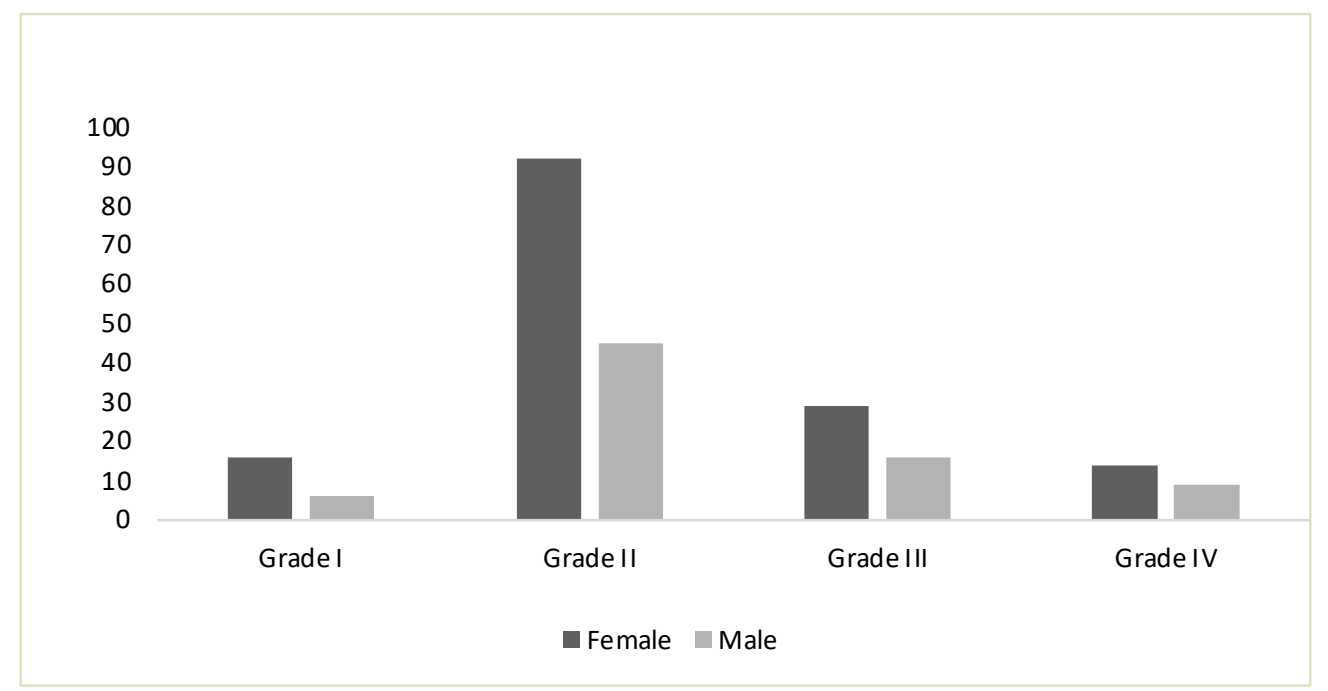

Figure 2. Gender and pterygium grading distribution

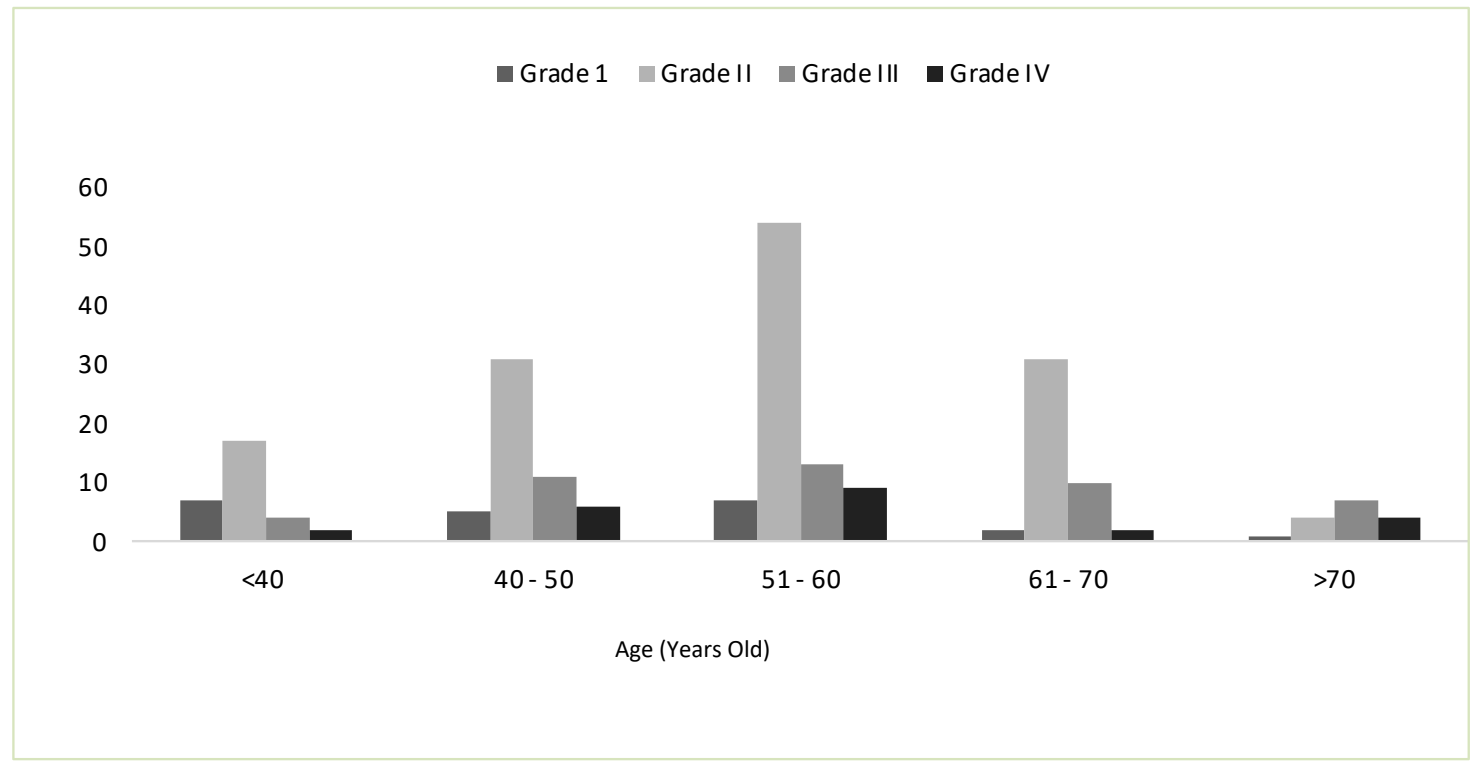

Figure 3. Age and pterygium grade distribution

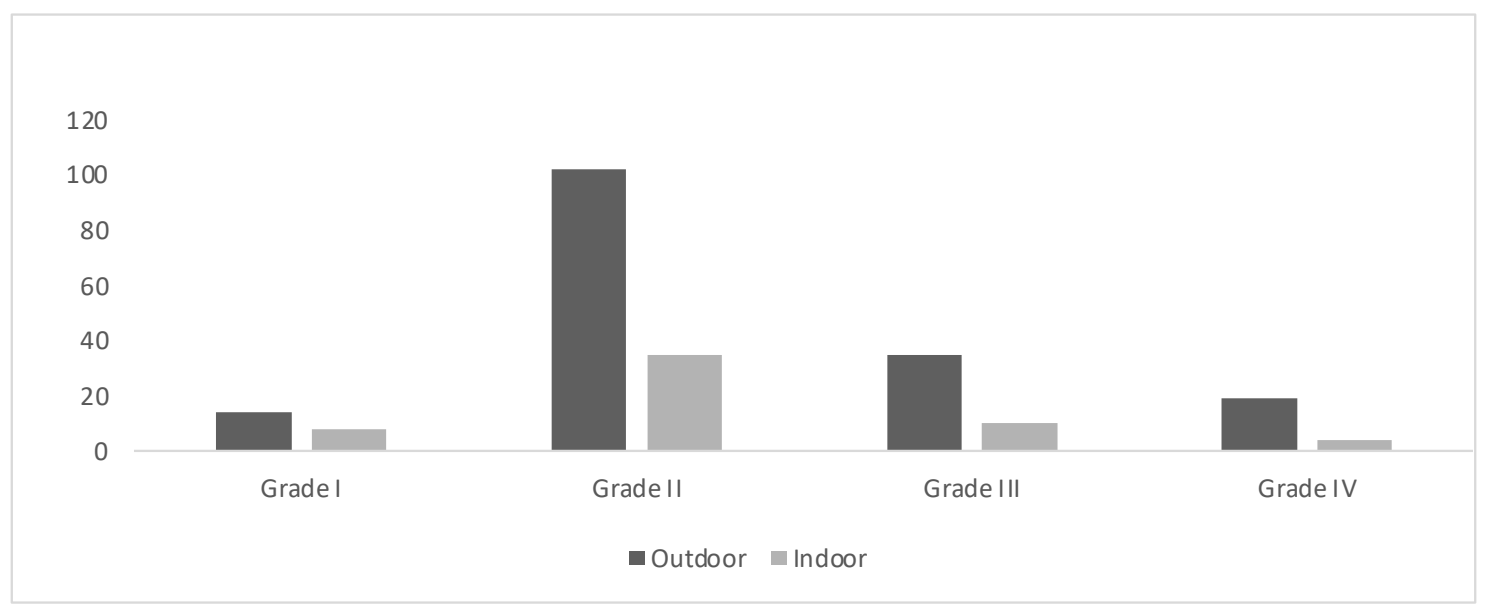

Figure 4. Occupation and pterygium grades distribution 
(farmers and fishers), while South Korean people are more service-dominant than work indoors. ${ }^{14-16}$

On gender, most studies on the same topic reported a higher prevalence of men compared to women. In the Riau study, men were 1.83 times more likely to get pterygium than women. ${ }^{6} \mathrm{~A}$ systematic review study also reported that men were more frequently diagnosed with pterygium with an OR of $2.32(95 \% \mathrm{Cl} 1.66$ to $3.23 ; \mathrm{I} 2=85 \%, \mathrm{p}<0.001)$ than women. ${ }^{3}$ Another study from Tibet showed that Chinese women were at a higher proportion than men with an OR of $1.6(95 \% \mathrm{Cl} 1.2-2.0) .{ }^{8}$ Our study showed a similar result with those from Tibet that the women made up a higher proportion at 151 (66.5\%) than men at 76 (33.5\%). The difference in gender proportion might be related to the distinct sample collection method and geographical structures between the Riau study and our study. The difference in working structure and culture might also cause a significant proportion of women working in Gunung Kidul compared to those in Riau. Additionally, we could not investigate the significance of gender proportion in our study due to the unavailability of the control group.

In this study, both the right eyes and left eyes were equally affected. This study was in line with the results from the Sumatra and Riau study. ${ }^{6,9}$ Additionally, according to a meta-analysis study, the increasing prevalence of pterygium is associated with outdoor activity, OR $1.76(95 \% \mathrm{Cl} 1.55-2) .^{3}$ Our study showed that those who worked outdoors have a higher proportion of pterygium (74.9\%) than those working indoors (25.1\%). However, the difference was not significant.

Pterygium could be best managed at earlier stages. Thus, early detection and prevention are paramount to successful treatment. As many were diagnosed during the event, our charity program proved that many individuals benefited from reaching out directly to the communities.

Although this program had some advantages, it had some disadvantages. First, the facilities were limited because it was not a standard-setting. Therefore, the results were not optimal as if it was done in a hospital-based. Second, there might be a risk that the community becomes less active in checking their eye health, only passively waiting for the following social service program that we can't be sure will be carried out routinely. Nevertheless, We hope to organize similar events to serve the communities in need as per our dedication.

\section{Conclusion}

The prevalence of pterygium increased with older age and peaked at a certain decade. Our study reported a peak age in the fifth decade among our study subjects. Women had a higher proportion than males. Those who worked outdoor had higher pterygium cases compared to those working indoor. Preventive measures such as wearing eye protection, sunglasses, goggles, or brimmed hats must be pursued, especially when someone's work is exposed to sunlight or dust.

Early detection and comprehensive management are still needed, considering the pterygium rate, which is still relatively high in rural areas such as Gunung Kidul. In order to maximize early detection, NGOs (Non-Governmental Organisations) such as BAZNAS can carry out the empowerment program. The participation of the community is an excellent example of increasing the early detection of diseases.

Empowerment of community components, community organizations, and primary health care needs to be explored more in the future for pterygium and other diseases such as glaucoma or cataracts that require early detection.

\section{Acknowledgement}

We would like to thank the Public Health Agency district Gunung Kidul and BAZNAS Gunung Kidul, who provided support throughout our initiative charity program.

\section{Conflict of interests}

None declared.

\section{References}

1. Asbell P, Brocks D. Cornea overview. Encycl Eye. 2010;522-31.

2. American Academy of Ophthalmology. Pterygium - Asia Pacific [Internet]. www.aao. 
org. 2015 [cited 2020 Nov 19]. Available from: https://www.aao.org/topic-detail/pterygiumasia-pacific

3. Liu L, Wu J, Geng J, Yuan Z, Huang D. Geographical prevalence and risk factors for pterygium: A systematic review and meta-analysis. BMJ Open. 2013;3(11).

4. Rany N. Relationship between working environment and fishermen's behaviors toward pterygium incidence in Kemang Village District of Pangkalan Kuras Pelalawan. KESKOM. 2017;3(4):153-158.

5. BPPK Kementerian Kesehatan RI 2013. Riset Kesehatan Dasar (RISKESDAS) Dalam Angka Daerah Istimewa Yogyakarta Tahun 2013 [Internet]. Available from https://www. pusat2.litbang.kemkes.go.id/wp-content/ uploads/2018/03/Riskesdas-Dalam-Angka-ProvDIY.pdf

6. Tan $\mathrm{CSH}$, Lim $\mathrm{TH}$, Koh WP, Liew GC, Hoh ST, Tan CC, et al. Epidemiology of pterygium on a tropical island in the Riau Archipelago. Eye. 2006;20(8):908-12.

7. BPKP. Profil Kabupaten Gunungkidul [Internet]. http://www.bpkp.go.id/. 2020 [cited 2020 Nov 20]. Available from: http://www.bpkp.go.id/diy/ konten/835/profil-kabupaten-gunungkidul

8. Wong TY, Foster PJ, Johnson CJ, Seah SKL, Tan DTH. The prevalence and risk factors for pterygium in an adult Chinese population in Singapore: The Tanjong Pagar survey. Am J Ophthalmol. 2001;131(2):176-83.

9. Cajucom-Uy H, Tong L, Wong TY, Tay WT, Saw SM. The prevalence of and risk factors for pterygium in an urban Malay population: The Singapore Malay Eye Study (SiMES). Br J Ophthalmol. 2010;94(8):977-81.

10. Rim THT, Nam J, Kim EK, Kim TI. Risk factors associated with pterygium and its subtypes in Korea: The Korean national health and nutrition examination survey 2008-2010. Cornea. 2013;32(7):962-70.

11. Gazzard G, Saw SM, Farook M, Koh D, Widjaja $D$, Chia $S E$, et al. Pterygium in Indonesia: Prevalence, severity and risk factors. $\mathrm{Br} \mathrm{J}$ Ophthalmol. 2002;86(12):1341-6.
Expectancy of the World Population [Internet]. worldometers.info. 2020 [cited 2020 Nov 22]. Available from: https://www.worldometers. info/demographics/life-expectancy/\#countriesranked-by-life-expectancy

13. Statistik badan pusat. Data Gunung Kidul 2018 (Metode Baru) [Internet]. https://ipm.bps. go.id/. 2019 [cited 2020 Nov 22]. Available from: https://ipm.bps.go.id/data/kabkot/metode/ baru/3403

14. Riau BPSPK. Angka Harapan Hidup 2017 [Internet]. https://kepri.bps.go.id. 2018 [cited 2020 Nov 22]. Available from: https://kepri.bps. go.id/dynamictable/2018/05/15/179/angkaharapan-hidup-2017.html

15. R. Hirschmann. Employed residents aged 15 years and above Singapore 2019 by industry [Internet]. https://www.statista.com. 2020 [cited 2020 Nov 22]. Available from: https://www.statista.com/ statistics/1009277/employed-residents-byindustry-singapore/

16. Plecher H. Employment by economic sector in South Korea 2020 [Internet]. https:// www.statista.com. 2020 [cited 2020 Nov 22]. Available from: https://www.statista.com/ statistics/604702/employment-by-economicsector-in-south-korea/

12. United Nations Population Division. Life 